\title{
PENGARUH KUALITAS LAYANAN DAN HARGA TERHADAP KEPUASAN PELANGGAN OKEJEK (Studi Kasus: Pada Kecamatan Medan Perjuangan Kota Medan)
}

\author{
Tri Melda Mei Liana
}

Fakultas Ekonomi dan Bisnis, Universitas HKBP Nommensen, Medan, Indonesia Email: $\underline{\text { liana25mei@gmail.com }}$

\section{DOI: https://doi.org/10.46880/methoda.Vol11No1.pp53-59}

\begin{abstract}
This study aims to determine the effect of service quality and price on Okejek's customer satisfaction (Case Study on the Medan Perjuangan District). The sample used in this study was 100 respondents using a questionnaire. From the results of multiple regression analysis, the service quality variable has a positive effect on customer satisfaction, the price variable has a negative effect on customer satisfaction. From the t-test results, the service quality variable is significant to customer satisfaction, the price variable is not significant to customer satisfaction. Based on the results of the F test, the variables of service quality and price together have a significant effect on customer satisfaction. From the results of testing the coefficient of determination $R 2$, service quality and price variables can explain customer satisfaction of $66.4 \%$ while the remaining $33.6 \%$ is explained by variables not examined.
\end{abstract}

Keywords: Service Quality, Price, Customer Satisfaction.

\begin{abstract}
ABSTRAK
Penelitian ini bertujuan untuk mengetahui pengaruh kualitas pelayanan dan harga terhadap kepuasan pelanggan Okejek (Studi Kasus Pada Kecaaatan Medan Perjuangan). Sampel yang digunakan dalam penelitian ini adalah 100 responden dengan menggunakan kuesioner. Dari hasil uji analisis regresi berganda variabel kualitas pelayanan berpengaruh positif terhadap kepuasan pelanggan, variabel harga berpengaruh negatif terhadap kepuasan pelanggan. Dari hasil uji $t$ variabel kualitas pelayanan signifikan terhadap kepuasan pelanggan, variabel harga tidak signifikan terhadap kepuasan pelanggan. Berdasarkan hasil uji F variabel kualitas pelayanan dan harga secara bersama-sama berpengaruh signifikan kepuasan pelanggan. Dari hasil pengujian koefisien determinasi $\mathrm{R}^{2}$ variabel kualitas pelayanan dan harga dapat menjelaskan kepuasan pelanggan sebesar 66,4\% sedangkan sisa nya 33,6\% dijelaskan oleh variabel yang tidak diteliti.
\end{abstract}

Kata Kunci: Kualitas Pelayanan, Harga, Kepuasan Pelanggan.

\section{PENDAHULUAN}

Di era modern sekarang ini, masyarakat mempunyai aktivitas yang beragam dan untuk memenuhi aktivitas tersebut masyarakat memerlukan adanya transportasi. Transportasi dapat berupa mobil pribadi, taxi, angkutan umum, kereta api, kapal laut bahkan pesawat terbang yang 
dapat mempermudah seseorang mencapai tujuan dengan waktu yang relative lebih singkat atau cepat. Di Indonesia terdapat berbagai macam transportasi yang bisa digunakan masyarakat seperti Kota Medan yang merupakan kota metropolitan yang menyediakan berbagai macam transportasi diantaranya kereta api, bus, taksi, dan lainlain.

Banyaknya jumlah penduduk di Kota Medan, membuat angkutan umum massal menjadi tidak nyaman karena harus berdesak-desakan dengan masyarakat lainnya jika ingin menggunakannya. Masyarakat selalu menginginkan kenyamanan dalam menggunakan transportasi publik, meskipun harus membayar lebih atas jasanya. Salah satu transportasi yang digunakan masyarakat untuk mempercepat aktivitasnya yaitu becak, karena dalam penggunaannya becak mampu mengantarkan penumpangnya bahkan sampai gang sempit, namun dalam penggunaanya harga yang ditawarkan oleh becak tidak sebanding dengan jarak tempuh yang akan dicapai oleh penggunanya. Layanan yang ditawarkan becak tentu saja menjadi memiliki daya tarik sendiri karena mampu mengantarkan penumpangnya hingga sampai ke depan rumah.

Seiring dengan berkembangnya teknologi saat ini terdapat aplikasi yang mengenalkan layanan pemesanan dengan menggunakan teknologi dan memakai standar pelayanan. Transportasi umum memakai sistem pangkalan di berbagai wilayah dan pada sembarangan tempat yang dianggap strategis untuk menunggu penumpangnya. Transportasi online yang beraneka ragam, dimulai dari Gojek, Grab, dan Uber dan juga Okejek yang melayani mulai dari pengantaran satu orang, lebih dari satu orang, makanan dan bahkan pengantarang barang. Dalam setiap pelayanannya memiliki kelebihan dan kekurangan masingmasing.

Okejek berbarengan dengan ekspansi GoJek, Okejek pun mengubah model layanan. Awalnya berasal dari kota Malang, pesanan pelanggan hanya lewat Whatsapp dan Blackberry Messenger, dan berkembang hingga dapat diunduh dalam sebuah aplikasi dengan menggunakan telepon seluler. Okejek menawarkan beberapa layanan online yaitu ojek atau pengantaran satu orang saja, kurir atau pengantaran barang, belanja, oke food atau pengantaran makanan dan oke car atau pengantaran lebih dari satu orang. Sebagai penyedia jasa berbasis aplikasi, umumnya costumer Okejek (yang termasuk golongan Pelajar/Mahasiswa, Wiraswasta, Pegawai, dll) karena masyarakat sekarang yang dinilai lebih cepat menyesuaikan diri dengan hal-hal yang baru. Walaupun terbilang baru tetapi sudah cukup banyak masyarakat yang menggunakan jasa Okejek, walaupun tidak dalam penggunaan rutin. Dalam Hal ini Semakin banyaknya tranaportasi online yang bermunculan akan dapat memberikan dampak pada ketatnya persaingan. Faktor yang menjadi penyebab terjadinya hal tersebut yakni ini menjadikan konsumen semakin selektif.

Konsumen akan memilih salah satu diantara pilihan alternatif yang menurutnya sesuai dengan yang diinginkannya. Mengantisipasi keadaan tersebut maka perusahaan Transportasi online khususnya Okejek harus bisa menciptakan kepuasan pelanggan. Kepuasan Pelanggan merupakan sebuah sasaran utama agar perusahaan dapat terus menerus berkembang. Pada saat ini banyak perusahaan yang semakin memahami arti penting dari kepuasan pelanggan dan menjalankan strategi guna memberikan kepuasan bagi pelanggan. Adapun Faktor - faktor yang mempengaruhi kepuasan pelanggan diantaranya adalah 
kualitas pelayanan dan persepsi harga. Kualitas Pelayanan merupakan unsur penentu dalam perusahaan untuk mempertahankan konsumen.

Persepsi harga merupakan tawaran kepada para pelanggan. Harga yang tepat adalah harga yang sesuai dengan kualitas jasa dan harga tersebut dapat memberikan kepuasan kepada pelanggan.

Berdasarkan hasil pra survey kepada 40 pelanggan Okejek dengan memberikan pertanyaan mengenai "Bagaimana kepuasan anda setelah menggunakan Okejek?". Hasil pra survey menunjukkan bahwa sebagian responden (6 orang/15\%) memiliki persepsi tidak puas terhadap Okejek.

Berdasarkan hasil pra survey kepada 40 pelanggan Okejek dengan memberikan pertanyaan mengenai "Bagaimana penilaian anda mengenai kualitas pelayanan Okejek?“. Hasil pra survey menunjukkan bahwa sebagian responden (5 orang/12,5\%) memiliki persepsi tidak baik terhadap kualitas pelayanan Okejek.

Berdasarkan hasil pra survey terhadap 40 pelanggan Okejek dengan memberikan pertanyaan mengenai "Bagaimana penilaian anda mengenai harga Okejek? ". Hasil pra survey menunjukkan sebagian responden (4 orang/10\%) memiliki persepsi mahal terhadap Okejek.

\section{TINJAUAN PUSTAKA}

\section{Kualitas Pelayanan}

Menurut Zeithmal dan Bitner (2008) menyatakan bahwa kualitas pelayanan merupakan total pengalaman yang hanya dapat dievaluasi oleh konsumen (Junni, 2017). Sedangkan menurut Lovelock dan Wirtz (2011) menyatakan bahwa kualitas pelayanan adalah tingkat keunggulan yang diharapkan dan pengendalian atas tingkat keunggulan tersebut untuk memenuhi keinginan konsumen (Junni, 2017).
Pengertian lain menurut Parasuraman, et.al. yang dikutip pada artikel penelitian kualitas Pelayanan merupakan dasar bagi pemasaran, karena inti produk yang dipasarkan adalah suatu kinerja (yang berkualitas), dan kinerjalah yang dibeli oleh pelanggan (Utami, 2013). Sedangkan menurut Fandy Tjiptono kualitas pelayanan merupakan tingkat keunggulan atau (excellent) yang diharapkan dan pengendalian atas keunggulan tersebut untuk memenuhi kebutuhan konsumen (Tjiptono, 2014). Kualitas pelayanan sebagai suatu usaha untuk mewujudkan kenyamanan terhadap konsumen agar konsumen merasa mempunyai nilai yang lebih diharapkan. Kualitas pelayanan diwujudkan melalui pemenuhan kebutuhan dan keinginan pelanggan serta ketetapan penyampaiannya dalam mengimbangi atau melampaui harapan pelanggan.

\section{Harga}

Harga adalah salah satu elemen bauran pemasaran yang menghasilkan biaya. Mungkin harga adalah elemen termudah dalam program pemasaran untuk disesuaikan fitur produk, saluran, dan bahkan komunikasi membutuhkan lebih banyak waktu. Harga juga mengkomunikasikan positioning nilai yang dimaksudkan dengan produk atau merek perusahaan ke pasar (Kotler, P. \& Keller, 2012). Sedangkan pada sumber lainnya harga adalah sejumlah uang yang ditagihkan atas suatu produk dan jasa atau jumlah dan nilai yang ditukarkan para pelanggan untuk memperoleh manfaat dari memiliki atau menggunakan suatu produk atau jasa (Effendi, 2010). Pengertian lainnya harga merupakan sejumlah uang yang dikeluarkan untuk sebuah produk atau jasa, atau sejumlah nilai yang ditukarkan oleh konsumen untuk memperoleh manfaat atau 
kepemilikan atau penggunaan atas sebuah produk atau jasa (Kotler \& Gary, 2013). Berdasarakan definisi diatas dapat disimpulkan bahwa harga adalah suatu sifat yang sangat sensitif, apabila ingin melakukan kegiatan bisnis konsumen dituntut mengeluarkan alat transaksi sebagai alat tukar agar dapat memiliki dan merasakan apa yang ingin di konsumsinya. Oleh karena itu harga sebisa mungkin sesuai dengan persepsi konsumen tentang produk atau jasa yang ditawarkan.

\section{Pengertian Kepuasan Pelanggan}

Kata kepuasan (satisfaction) berasal dari bahasa dari latin "satis" (artinya cukup baik, memadai) dan "facio" (melakukan atau membuat), Kepuasan bisa diartikan sebagai "upaya pemenuhan" (Tjiptono \& Chandra, 2011). Lalu menurut (Tjiptono, 2012) kepuasan pelanggan adalah perasaan senang atau kecewa seseorang yang muncul setelah membandingkan antara persepsi terhadap kinerja (hasil) suatu produk dengan harapanharapannya. Dan (Supranto \& Limakrisna, 2012) kepuasan pelanggan merupakan label yang digunakan oleh pelanggan untuk meringkas suatu himpunan aksi atau tindakan yang terlihat, terkait dengan produk dan jasa.

\section{METODOLOGI PENELITIAN}

\section{Populasi dan Sampel}

Populasi dalam penelitian ini adalah masyarakat Kecamatan Medan Perjuangan Kota Medan Sumatera yang pernah menggunakan jasa Okejek.

Menurut (Aditi \& Hermansyur, 2017) menyarankan untuk menggunakan sampel minimal 100 responden untuk memberikan hasil yang lebih baik. Sampel dalam penelitian ini sesuai dengan pendapat Hair yaitu 100 Responden.

Dalam penelitian ini, Metode
Pengambilan Sampel menggunakan nonprobability sampling dengan teknik purposive sampling. Untuk menentukan sampel berdasarkan tujuan penelitian sesuai dengan kriteria yang telah ditentukan, kriteria pengambilan sampel dalam penelitian ini adalah masyarakat Kota Medan yang sudah menggunakan jasa Okejek 2 kali selama 3 bulan terakhir. Kuisoner yang sudah dirancang dengan menggunakan kuisoner online (google form) yang kemudian di sebarkan melalui media sosial facebook, whatsapp dan instagram.

\section{HASIL DAN PEMBAHASAN}

\section{Pengujian Hipotesis}

\section{Analisis Regresi Berganda}

Analisis linier berganda dilakukan untuk mengetahui seberapa besarnya pengaruh antara variabel bebas yaitu, kualitas pelayanan dan harga terhadap variabel terikat kepuasan pelanggan

$$
\mathbf{Y}=\mathbf{a}+\mathbf{b}_{1} \mathbf{X}_{1}+\mathbf{b}_{2} \mathbf{X}_{2}+\mathbf{e}
$$

Tabel 1. Regresi Linear Berganda Coefficients $^{\text {a }}$

\begin{tabular}{|l|r|r|r|}
\hline \multirow{2}{*}{ Model } & \multicolumn{2}{|c|}{$\begin{array}{c}\text { Unstandardized } \\
\text { Coefficients }\end{array}$} & \multicolumn{1}{c|}{$\begin{array}{c}\text { Standardized } \\
\text { Coefficients }\end{array}$} \\
\cline { 2 - 4 } & \multicolumn{1}{|c|}{ B } & \multicolumn{1}{c|}{ Std. Error } & \multicolumn{1}{c|}{ Beta } \\
\hline Constant) & 6.989 & 1.365 & \\
$\begin{array}{l}\text { Kualitas } \\
\text { Pelayanan }\end{array}$ & .225 & .042 & .477 \\
Harga & -.056 & .065 & -.076 \\
\hline
\end{tabular}

a. Dependent Variable: KepuasanPelanggan

Berdasarkan tabel 1 diatas dapat diperoleh persamaan regresi linear berganda sebagai berikut:

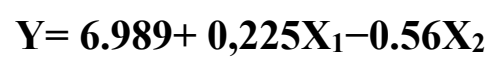

1. Dari persamaan regresi linear berganda diatas, dapat dijelaskan bahwa besarnya konstanta positif. Ini menunjukkan bahwa jika tidak ada perubahan variabel kualitas pelayanan dan harga, maka kepuasan pelanggan konsumen tinggi.

2. Variabel kualitas pelayanan bernilai positif, yang artinya jika variabel kualitas 
pelayanan naik 1\% maka maka kepuasan pelanggan akan naik sebesar 0,225 dengan asumsi variabel harga tetap.

3. Variabel harga bernilai negatif, yang artinya jika variabel harga naik sebesar $1 \%$ maka keputusan pembelian akan turun sebesar 0,056 dengan asumsi variabel kualitas pelayanan tetap.

\section{Uji Parsial (Uji- t)}

Dengan melakukan uji $t$ kita akan mengetahui sejauh mana pengaruh satu variabel independen secara individual dalam menerangkan variabel dependen, pada signifikansi 5\% dan df (derajat kebebasan) $=\mathrm{n}-\mathrm{k}$ jadi $\mathrm{df}=100-3=97 \mathrm{t}$ tabel adalah sebesar 1,661. ( $\mathrm{N}=$ jumlah sampel dan $\mathrm{k}=$ jumlah semua variabel). Uji ini dilakukan dengan membandingkan t-hitung dengan $t$ tabel.

Kriteria Pengambilan keputusan:

$\mathrm{H}_{0}$ diterima jika taraf signifikansi $>\alpha=5 \%$ atau $t_{\text {hitung }}>t_{\text {tabel }}$

$\mathrm{H}_{1}$ diterima jika taraf signifikansi $<\alpha=5 \%$ atau $t_{\text {hitung }}>\mathrm{t}_{\text {tabel }}$

Tabel 2. Uji Parsial (Uji t)

Coefficients $^{\mathrm{a}}$

\begin{tabular}{|c|c|c|}
\hline Model & $\mathrm{t}$ & Sig. \\
\hline $1 \quad$ (Constant) & 5.120 & .000 \\
\hline KualitasPelayanan & 5.354 & .000 \\
\hline Harga & -.853 & .396 \\
\hline
\end{tabular}

a. Dependent Variable: KepuasanPelanggan

a. Variabel X1 (Kualitas Pelayanan)

Hasil statistik uji t untuk variabel harga diperoleh nilai $t_{\text {hitung }}$ sebesar 5.354 dan $t_{\text {tabel }}$ sebesar 1,661 maka $t_{\text {hitung }}<t_{\text {tabel }}$ $(6,748<1,661)$ dengan signifikansi sebesar 0,000 lebih kecil dari 0,05 (0,000 $>0,05)$ maka dinyatakan bahwa kualitas pelayanan berpengaruh secara positif dan signifikan terhadap kepuasan pelanggan $\mathrm{H}_{1}$ diterima dan $\mathrm{H}_{0}$ ditolak. b. Variable X2 (Harga)

Hasil statistik uji t untuk variabel Harga diperoleh nilai thitung sebesar -0.853 dan $\mathrm{t}_{\text {tabel }}$ sebesar 1,661 maka $\mathrm{t}_{\text {hitung }}<\mathrm{t}_{\text {tabel }}$ $(0.853<1,661)$ dengan signifikansi sebesar 0,0,396 lebih besar dari 0,05 $(0.396>0,05)$ maka dinyatakan bahwa harga berpengaruh secara negatif tidak signifikan terhadap kepuasan pelanggan. Artinya $\mathrm{H}_{2}$ ditolak dan $\mathrm{H}_{0}$ diterima.

\section{Uji Simultan (Uji f)}

Uji f merupakan uji serentak untuk mengetahui variabel bebas (kualitas pelayanan dan harga) mempunyai pengaruh secara bersama-sama terhadap variabel terikat (kepuasan pelanggan).

Kriteria Pengambilan keputusan:

$\mathrm{H}_{0}$ diterima jika taraf signifikansi $>\alpha=5 \%$ atau $f_{\text {hitung }}>\mathrm{f}_{\text {tabel }}$

$\mathrm{H}_{1}$ diterima jika taraf signifikansi $<\alpha=5 \%$ atau $\mathrm{f}_{\text {hitung }}>\mathrm{f}_{\text {tabel }}$

Tabel 3. Uji Simultan (Uji F)

ANOVA $^{\mathrm{a}}$

\begin{tabular}{|l|r|r|r|c|c|}
\hline Model & $\begin{array}{r}\text { Sum of } \\
\text { Squares }\end{array}$ & df & $\begin{array}{r}\text { Mean } \\
\text { Square }\end{array}$ & F & Sig. \\
\hline 1 Regression & 50.291 & 2 & 25.145 & 14.597 & $.000^{\mathrm{b}}$ \\
Residual & 167.099 & 97 & 1.723 & & \\
Total & 217.390 & 99 & & & \\
\hline
\end{tabular}
a. Dependent Variable: KepuasanPelanggan
b. Predictors: (Constant), Harga, KualitasPelayanan

Dengan melihat Tabel 3 Fhitung sebesar 14.597 dengan nilai $F_{\text {tabel }}$ sebesar 2,31 $(14.597>2,31)$ nilai signifikan 0,000 pada tarif signifikan sebesar 0,05 $(0,000<0,05)$. Jadi data disimpulkan bahwa $F_{\text {hitung }}>F_{\text {tabel }}$

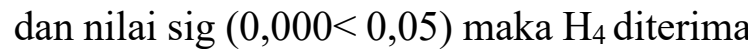
dan $\mathrm{H}_{0}$ ditolak, sehingga variabel kualitas pelayanan, harga, secara simultan berpengaruh signifikan terhadap kepuasan pelanggan OKEJEK. 


\section{Koefisien Determinasi $\left(\mathbf{R}^{\mathbf{2}}\right)$}

Koefisien Determinasi $\left(\mathrm{R}^{2}\right)$ untuk mengukur seberapa jauh kemampuan model dalam menerangkan variabel dependen yang diukur dalam persentase nilai $\mathrm{R}^{2}$ yang kecil berarti kemampuan variabel-variabel independen dalam menjelaskan variabel dependen sangat terbatas. Adapun hasil dari koefisin determinasi dapat dilihat pada tabel berikut:

Tabel 4. Koefisien Determinasi $\left(\mathrm{R}^{2}\right)$

\begin{tabular}{|c|c|c|c|c|c|}
\hline \multirow[b]{3}{*}{ Model } & \multirow[b]{3}{*}{$\mathrm{R}$} & \multirow{3}{*}{$\begin{array}{c}\text { R } \\
\text { Square }\end{array}$} & \multicolumn{3}{|c|}{ Model Summary $^{\mathbf{b}}$} \\
\hline & & & Adjusted & $\begin{array}{l}\text { Std. Error } \\
\text { of the }\end{array}$ & $\begin{array}{l}\text { Durbin- } \\
\text { Watson }\end{array}$ \\
\hline & & & R Square & Estimate & \\
\hline 1 & $.815^{\mathrm{a}}$ & .664 & .573 & 276.257 & 1.125 \\
\hline
\end{tabular}

a. Predictors: (Constant), Kualitas Pelayanan, Harga

b. Dependent Variable: Kepuasan Pelanggan

Berdasarkan hasil Tabel 4. dapat disimpulkan bahwa variabel kualitas pelayanan dan harga dapat menjelaskan kepuasan pelanggan sebesar 0,664 atau $66,4 \%$ sedangkan sisanya 0,336 atau $33,6 \%$ dijelaskan oleh variabel lain yang tidak diteliti.

\section{PEMBAHASAN}

\section{Pengaruh Kualitas Pelayanan Terhadap Kepuasan Pelanggan}

Berdasarkan hasil uji ditunjukkan bahwa variabel kualitas pelayanan memberikan pengaruh yang signifikan terhadap variabel kepuasan pelanggan. Hal ini menunjukkan bahwa kualitas pelayanan memang merupakan salah satu penyebab mengapa konsumen melakukan pembelian. Angkaangka dari hasil uji menunjukkan bahwa setiap pernyataan yang digunakan untuk mengukur hubungan antara kualitas pelayanan dengan kepuasan pelanggan sudah mewakili persetujuan responden bahwa yang membuat mereka puas pada okejek adalah kualitas pelayanannya.
Hal ini sejalan dengan penelitian yang berjudul Pengaruh Kualitas Pelayanan, Persepsi Harga, dan Citra Merek Terhadap Kepuasan Pelanggan Pengguna Jasa Tranportasi Ojek Online (Go-Jek). Terdapat hasil penelitian pengaruh kualitas pelayanan terhadap kepuasan pelanggan secara parsial berpengaruh signifikan (Zahra, 2017).

\section{Pengaruh Harga Terhadap Kepuasan Pelanggan}

Berdasarkan hasil uji ditunjukkan bahwa variabel harga memberikan pengaruh yang negatif tidak signifikan terhadap variabel kepuasan pelanggan. Hal ini menunjukkan bahwa harga tidak berpengaruh terhadap kepuasan pelanggan. Faktor yang menyebabkan tidak signifikan adalah jumlah sampel dan jumlah variabel. Jika jumlah sampel di tambah akan mendapatkan hasil yang berbeda. Angka-angka dari hasil uji menunjukkan bahwa setiap pernyataan yang digunakan untuk mengukur hubungan antara harga dengan kepuasan pelanggan sudah mewakili persetujuan responden. Hasil yang didapat dilapangan bahwa harga pada okejek sudah tergolong mahal, hanya harapannya apabila memang harga pada okejek harus naik tetapi perlu diimbangi dengan perbaikan kualitas pelayanan dan promosinya sehingga sebanding dengan biaya yang telah di keluarkan.

Hal ini tidak sejalan dengan penelitian yang dilakukan oleh (Zahra, 2017) dengan judul Pengaruh Kualitas Pelayanan, Persepsi Harga, dan Citra Merek Terhadap Kepuasan Pelanggan Pengguna Jasa Tranportasi Ojek Online (Go-Jek). Terdapat hasil penelitian pengaruh harga terhadap kepuasan pelanggan secara parsial berpengaruh positif dan tidak signifikan. 


\section{KESIMPULAN}

Dari hasil penelitian, penulis dapat memberikan kesimpulan sebagai berikut:

1. Berdasarkan hasil uji t variabel kualitas pelayanan berpengaruh positif dan signifikan terhadap kepuasan pelanggan okejek.

2. Berdasarkan hasil uji t variabel harga berpengaruh negatif dan tidak signifikan terhadap kepuasan pelanggan okejek.

3. Berdasarkan hasil uji f variabel kualitas pelayanan dan harga secara simultan berpengaruh signifikan terhadap kepuasan pelanggan.

4. Berdasarkan Dari uji kefisien determinasi (R2) variabel kualitas pelayanan harga, promosi, berpengaruh sebesar $66,4 \%$ sisanya $33.6 \%$ dipengaruhi oleh variabel lain yang tidak di teliti.

\section{DAFTAR PUSTAKA}

Aditi, B., \& Hermansyur, H. M. (2017).

Pengaruh Kualitas Produk, Citra

Merek, Harga, dan Promosi terhadap

Keputusan Pembelian Mobil Merek

Honda di Kota Medan. JKBM (Jurnal

Konsep Bisnis Dan Manajemen), 3(2), 154-165.

https://doi.org/10.31289/jkbm.v3i2.34

2

Effendi, G. M. (2010). Transformasi

Manajemen Pemasaran + Membangun

Citra Negara. Jakarta: Sagung Seto.

Junni, D. P. (2017). Perilaku Konsumen dalam Bisnis Kontemporer. Bandung:

Alfabeta.

Kotler, P. \& Keller, K. L. (2012).

Manajemen Pemasaran (Edisi ke-1).

Jakarta: Penerbit Erlangga.

Kotler, P., \& Gary, A. (2013). Prinsip-

Prinsip Pemasaran (Edisi ke-1).

Jakarta: Penerbit Erlangga.

Supranto, \& Limakrisna, N. (2012).

Pengukuran Tingkat Kepuasan

Pelanggan. Jakarta: Rineka Cipta.

Tjiptono, F. (2012). Strategi Pemasaran

(Edisi ke-3). Yogyakarta: Andi Offset.

Tjiptono, F. (2014). Pemasaran Jasa (Edisi ke-4). Yogyakarta: Andi Offset.

Tjiptono, F., \& Chandra, G. (2011). Service Quality and Satisfuction (Edisi ke-3).

Yogyakarta: Andi Offset.

Utami, C. W. (2013). Manajemen

Pemasaran Jasa. Jakarta: BayuMedia.

Zahra, A. (2017). Pengaruh Kualitas Pelayanan, Persepsi Harga, dan Citra Merek Terhadap Kepuasan Pelanggan Pengguna Jasa Tranportasi Ojek Online (Go-Jek). Universitas Negeri Yogyakarta. 